\title{
REFLEXIONES SOBRE DEMOCRACIA, POLÍTICA E IGUALDAD ENTREVISTA A AGUSTÍN SQUELLA
}

Sonia Montecino Aguirre 


\section{AGUSTÍN SQUELLA NARDUCCI}

Doctor en Derecho, Profesor de Filosofía del Derecho en la Universidad de Valparaíso y de la Universidad Diego Portales. Miembro de Número de la Academia de Ciencias Sociales, Políticas y Morales del Instituto de Chile. Premio Nacional de Humanidades y Ciencias Sociales en el 2009. 


\section{REFLEXIONES SOBRE DEMOCRACIA, POLÍTICA E IGUALDAD Entrevista a Agustín Squella}

Sonia Montecino: ¿Cuáles serían, desde su perspectiva, los nudos centrales que enfrenta la política-gubernamental, del Estado y de los partidos- en el Chile de hoy?

Agustín Squella: El Estado no debe ser reducido, sino modernizado; un proceso que comenzó hace algunos años, aunque de una manera intermitente y no suficientemente planificada, y que debe estar regido por la idea de que la existencia del Estado es tan inevitable como necesaria para el desarrollo de los pueblos y el bienestar de las personas, salvo que quisiéramos retroceder a un estado de naturaleza que se parecería más al que describió Hobbes que Rousseau, esto es, no de paz, abundancia y felicidad, sino de tinieblas, soledad y guerra de todos contra todos.

No puede partirse de la idea de la maldad estatal, puesto que, en caso de hacerlo, cada vez que alguien se haga con el poder del Estado, o con parte de este, se sentirá fuera de lugar y no suficientemente estimulado a utilizar debidamente dicho poder. Un poder, en cualquier caso, que debe ser limitado. Todo poder, en verdad, tiene que ser limitado, y no solo el poder político, puesto que es propio del poder tender a expandirse, con la consiguiente posibilidad de producir daño a las personas. Pero así como el Estado debe ser limitado en su poder, también deben serlo el poder militar, el poder económico, el poder de los medios, e incluso el que ostentan organizaciones de carácter espiritual, puesto que todos ellos tienen capacidad de producir daño si no están debidamente regulados.

En cuanto al Gobierno -y esto vale especialmente para el actual-, debe ser capaz de atraer a la función pública tanto a hombres del Estado como a hombres de Estado. Llamo "hombre del Estado" a aquel que trabaja con gusto y eficiencia en este, que conoce y aprecia la función pública tanto en las posibilidades de servicio que ella ofrece como en los límites que reconoce, y que acepta sin quejas los deberes que pesan sobre los funcionarios. El "hombre del Estado" es lo que se acostumbra identificar como un meritorio "servidor público" y no es necesario que para serlo se tengan que ocupar altos cargos. Y llamo "hombre de Estado" a aquel que, junto con reunir las condiciones antes señaladas, se muestra a la altura de las especiales exigencias de los cargos públicos de mayor jerarquía, que es capaz de acumular una excepcional experiencia en el manejo de los asuntos que le conciernen, y que procede en estos con certera visión de mediano y largo plazo. El "hombre de Estado" es lo que suele llamarse "estadista", y sus aptitudes se aprecian en el desempeño de funciones públicas relevantes.

Pues bien, si hay sectores y partidos políticos que por largo tiempo han pregonado la maldad estatal, recelado y hasta denostado lo público a favor de lo privado, y asegurado que el bienestar de las personas proviene únicamente de su esfuerzo y capacidad de superación y emprendimiento y no de políticas ni decisiones públicas, ¿cómo pueden tales sectores y partidos atraer hacia la función pública a personas idóneas cuando se hacen 
con el gobierno y tienen que ser ellos los que gestionen los ministerios y servicios que antes denunciaron como un mal o cuando menos como una amenaza para la libertad, la iniciativa individual y el buen funcionamiento de los mercados?

En cuanto a los partidos políticos, tienen hoy pocos simpatizantes, aun menos militantes y un número todavía menor de militantes activos, algo que no parece preocupar demasiado a quienes los dirigen, puesto que de ese modo pueden controlar mejor a quienes hacen vida de partido. Otro abuso flagrante de los partidos, al menos a nivel de lenguaje, es que se hayan apropiado de una hermosa palabra - "sensibilidades"- para aludir a lo que al interior de cada uno de ellos no pasan de ser camarillas u grupos de poder que se muestran los dientes y disputan la conducción de las respectivas colectividades. Y lo tercero es que los partidos solo parecen servir a sus militantes mientras resultan funcionales para hacer una carrera política personal u obtener trabajo en el aparato del Estado.

Los partidos son indispensables para la democracia, hasta el punto de que esta no es posible sin ellos, al menos en la única modalidad en que la democracia puede ser practicada en el tipo de sociedades extensas y complejas en que nos toca vivir. Así las cosas, el debilitamiento y desprestigio de los partidos traen consigo un similar debilitamiento y desprestigio de la propia democracia. Los líderes de los partidos no saben cuánto daño hacen a la democracia con sus malas prácticas, en especial con la completa subordinación a que someten a las colectividades en que militan a sus personales expectativas y ambiciones. Hemos sido testigos en los últimos años de políticos que abandonan sus partidos, o se hacen expulsar de estos, solo porque advierten que en ellos ya no pueden hacer una carrera política exitosa, pasándose incluso en tales casos del lado de quienes siempre fueron sus adversarios. Es claro que la política no es una actividad humana que se haga a partir de los mejores sentimientos del corazón humano, pero tampoco es necesario hacerla desde los peores. Y el resentimiento y el despecho se cuentan ciertamente entre los peores.

Por último -y excusas por lo extenso de esta respuesta-, el sistema binominal para elegir a nuestros senadores y diputados ha hecho un gran daño, puesto que, junto con igualar el poder político que tienen en el Congreso tanto la primera como la segunda mayoría, excluyendo a las minorías, ha acostumbrado a quienes postulan a tales cargos a no competir mayormente entre sí por las preferencias de los ciudadanos.

S.M.: ¿Qué diferencias y semejanzas percibes en los movimientos sociales del siglo XX y los de los albores del siglo XXI? ¿Tienen las mismas características o se trata más bien, en el caso de los últimos, de "acciones sociales" que demandan materias puntuales?

A.S.: Lo que pasa es que las personas empezaron a tomarse los derechos en serio, incluidos los de carácter social -a la salud, a la educación, al trabajo, a una previsión oportuna y justa-, y a exigir que todos los poderes del Estado -ejecutivo, legislativo y judicial- se los tomen igualmente en serio. Los derechos fundamentales no son ya unas vagas entelequias que reflejen meras utopías, sino que, debida y felizmente positivados en el derecho interno de los estados y en tratados internacionales, son algo de lo que los individuos toman cada vez mayor conciencia y empiezan a reclamar por su efectiva garantía, de manera que no se reduzcan a letra muerta escrita en el papel de las constituciones políticas y de los pactos internacionales de derechos humanos. 
Si por largo tiempo viene hablándose de derechos fundamentales, no podemos sorprendernos de que haya llegado el momento en que sus titulares crean que efectivamente los tienen y que alguien debe responder por ellos.

Con todo -y aun a riesgo de sonar impopular-, considero que también es necesario preguntar y preguntarnos acerca de cuáles son nuestros deberes. En la primera clase que doy a los alumnos de primer año en la Universidad procuro hacerles ver que han llegado allí merced al ejercicio de un derecho -el derecho a la educación-, pero que, obtenida ya la matrícula del caso y el asiento que ocupan en la sala, deben empezar a pensar en los deberes que impone la condición de estudiante universitario. Me refiero a cosas básicas, como asistir a clases, estudiar regularmente, preparar a conciencia las distintas materias, en el entendido de que a la Universidad no se va a tramitar un título profesional, sino a iniciar un proceso de formación en una determinada área del saber. Y digo "iniciar", puesto que bien sabemos que los estudios de pregrado no son suficientes y que siempre será preciso prolongarlos con cursos y programas de postítulo y posgrado.

Sin embargo, son pocos los que quieren oír hablar de deberes. Se ha instalado hoy en la educación, y también en la de carácter superior, lo que alguien ha llamado "conspiración contra la dificultad". Todo tiene que resultar fácil, sin esfuerzo, sin complicaciones, en circunstancias de que educarse, al menos a nivel superior, y ni qué decir universitario, no es ni puede ser algo para nada fácil. Por momentos tengo la sensación de que algunos estudiantes creen que el derecho a la educación incluye el de ser aprobados en las distintas asignaturas, lo cual, al menos en parte, es producto de que la lógica del parvulario -la educación como un juego- se ha expandido a la educación básica, a la media e incluso a la de tipo superior. El mayor descaro en tal sentido fue una pintada que leí alguna vez en uno de los muros de la Universidad Complutense de Madrid: "Aprobar es un derecho humano".

S.M.: ¿Cómo influye el pensamiento católico y conservador en las demandas de transformaciones culturales ligadas a las relaciones de género y de los derechos de las diferencias sexuales respecto a la igualdad?

A.S.: No solo en esas materias, sino en todas, el pensamiento católico conservador -y lo pongo de esta manera puesto que no hay un solo pensamiento católico- ha tenido en Chile una influencia desmesurada. Pensemos, sin ir más lejos, como la jerarquía de la Iglesia católica, con la complicidad de parlamentarios católicos y medios de comunicación igualmente católicos, o simplemente conservadores, consiguieron retrasar hasta los inicios del siglo XXI una ley de divorcio vincular que, por lo demás, quedó plagada de concesiones a los sectores conservadores que, confundiendo el matrimonio sacramento de las Iglesias con el matrimonio civil de la República, intentaron hasta el último momento -oprobiosa campaña de spots sobre los peligros de ser hijo de padres divorciados que transmitió profusamente un canal católico de televisión- que el segundo continuara rigiéndose por los dogmas que son propios del primero, pronosticando incluso que el país se precipitaría en las tinieblas morales si se aprobada una ley de divorcio, un vaticinio tan histérico como engañoso, y que por cierto no se cumplió. La paradoja es que muy pocos años después esos mismos sectores tienen que mostrarse dispuestos 
a discutir ahora sobre uniones de hecho o acerca del matrimonio entre personas del mismo sexo, como mañana tendrán que hacerlo sobre despenalización del aborto en determinadas circunstancias -como violación de la mujer embarazada, por ejemplo-, y, asimismo, sobre eutanasia, aunque recurrirán probablemente al discurso y a la denuncia de siempre para retrasar, no digo la aprobación, sino la simple discusión de asuntos como esos. A saber, que el país va transitando por una suerte de despeñadero moral.

Hay que recordar que el pensamiento católico -y hay que distinguirlo del pensamiento cristiano, puesto que este, según me parece, es mucho más abierto y tolerante que aquel- se opuso en su momento a instituciones como el matrimonio civil, los cementerios laicos y la creación de un registro civil de nacimientos y defunciones. Me imagino que hoy todos los católicos se avergüenzan de ello, aunque lo mejor sería que aprendieran de una vez la lección de que no pueden imponer sus creencias al grueso de la sociedad civil y de que las siempre pronosticadas tinieblas morales no caen sobre un país porque aprueba leyes sobre materias como esas.

El pensamiento católico trató durante siglos a las mujeres como seres inferiores, reducidas apenas a un vientre que asegurara la reproducción de la especie y la satisfacción del instinto sexual masculino, y ni qué decir de su implacable aversión a lo que su pregunta llama "minorías sexuales".

En materia sexual no hay opciones ni preferencias ni inclinaciones. Hay caracteres. La heterosexualidad es un carácter, una condición, lo mismo que la homosexualidad, y no es por tanto del caso creer que las personas, llegadas a cierto momento de sus vidas, optan, prefieren o se inclinan por una determinada condición sexual. Tienen una condición sexual y no es que opten por ella o la prefieran.

Por último, permítame distinguir también entre religiones e Iglesias. El catolicismo es una Iglesia, mientras que el cristianismo es una religión. Como dice Vattimo, la diferencia que hay entre religiones e iglesias es la misma que existe entre el arte y los museos o -dicho ahora en jerga deportiva- es la misma que hay entre el fútbol y los clubes de fútbol. A mi juicio, el mayor daño en la historia de la Humanidad lo han producido las Iglesias y sus clérigos, y no las religiones y sus habitualmente amables fundadores.

No tengo ningún título para dar consejos a los católicos, ni a nadie, pero el mejor camino para su Iglesia sería retomar el mensaje y la senda del cristianismo de los evangelios y no el de la lectura de los pontífices, y volver a ser la religión -perdón, la Iglesia- no de la verdad y el dogma, sino del amor y la caridad; no la del poder, sino la de la compasión; no la de los siervos, sino la de los amigos de Jesús; no la de la disciplina, sino la de las interpretaciones; y no la de los valores que se declaran, sino la de las virtudes que se practican.

S.M.: Desde su punto de vista, ies posible que el liberalismo económico ostentado por la derecha chilena sea coherente con un liberalismo cultural?

A.S.: En Chile no hemos tenido nunca liberalismo en el sentido completo del término. Los pocos liberales chilenos, tanto en el XIX como en el XX, fueron siempre mirados como unas plantas exóticas, cuando no definitivamente tóxicas. En Chile ganó Martín Rivas, no Bilbao, como dice Darío Oses. Nuestros principales y escasos liberales 
debieron pasar largas temporadas en el exilio. De manera que lo que hemos tenido en Chile es liberalismo económico - "liberismo", como también se dice-, o sea, un liberalismo en la más empobrecida de sus versiones (el neoliberalismo) y no, o no de manera suficiente, uno de carácter político y menos todavía de tipo cultural que reconozca la autonomía de las personas no solo para decidir y pensar cuáles creencias adoptar, sino qué idea de bien deben profesar y cuál tipo de vida llevar adelante para realizar esa idea de la mejor manera posible. O sea, hemos sido más libres a la hora de comprar y vender, al momento de entrar y salir de los supermercados, mas no completamente a la hora de elegir a nuestros representantes y de desarrollar formas de vida autónomas y diversas.

¿Cuántos que se dicen liberales votaron favorablemente la Constitución de 1980, liberal por excelencia? ¿Cuántos dijeron "Sí" a Pinochet en el plebiscito de 1988, en circunstancias de que mucho antes todos -digo todos- sabíamos de las violaciones masivas, sistemáticas y prolongadas a los derechos humanos, llevadas a cabo por agentes del Estado entrenados y destinados a practicar tales violaciones en nombre de la así llamada seguridad nacional? ¿Cuántos restaron sus votos hasta las reformas constitucionales de 2005 para eliminar a los senadores vitalicios y designados y para restablecer la plena subordinación del poder militar al poder político?

Voy a ir todavía más lejos: el verdadero líder de la significativa mayor parte de la derecha chilena, aquel al que verdaderamente admiran y añoran, es el general Augusto Pinochet. El propio Presidente Piñera, un hombre de derecha con chispazos democratacristianos, es mal visto por buena parte de nuestra derecha, simplemente porque votó No en el antes mencionado plebiscito y porque en su hora flirteó un poco con el PDC, un partido, este último, que tampoco es liberal. El único democratacristiano liberal que he conocido fue Edgardo Boeninger, con lo cual no quiero decir que reste valor a ese afortunado pacto de centroizquierda que forman (¿formaron?) ese mismo partido y el PRSD, el PS y el PPD.

Dicho de una manera simple: si las libertades reconocen siempre un límite, algo así como una línea del horizonte que no debemos traspasar (la libertad para mover mis puños termina justo allí donde comienza la nariz de mis semejantes), liberal es aquel que está interesado en empujar más allá la línea del horizonte, ampliando de ese modo el ámbito de la libertad, mientras los conservadores procuran atraer más acá esa misma línea, achicando el espacio de la libertad.

Pero si en Chile ha predominado una mentalidad conservadora, de un tiempo a esta parte, y de manera por lo demás acelerada, las cosas han empezado a cambiar, especialmente en la base social del país -cada vez más liberal política y culturalmente hablandoversus unas elites - de la política, de la educación, de los medios, de las empresas, de las Iglesias- que asisten perplejas, temerosas e inseguras al cambio de las cosas.

S.M.: Reflexionando desde un punto de vista filosófico-antropológico, "civilizatorio" y de larga duración, ¿cómo caracterizaría el momento de las sociedades contemporáneas y específicamente de Chile?

A.S.: Las sociedades actuales son demasiado diversas como para dar un juicio que valga para todas ellas. Incluso una sociedad determinada cualquiera -la chilena, por 
ejemplo-acoge suficiente diversidad como para tener que andarse con cuidado a la hora de las generalizaciones. Con todo, es claro que hay una insatisfacción con el capitalismo y con las desigualdades que este produce. ¿En qué momento -me pregunto- dejamos de hablar de "capitalismo" y sustituimos alegremente esa fea palabra por otra que suena mejor, como es el caso de "libre mercado"? ¿En qué momento dejamos de hablar de "igualdad" y nos conformamos con la mucho más blanda "equidad"? ¿Cuándo dejamos de hablar de "trabajo" para hablar de "empleo" e incluso de "pega", como se hace hoy cuando se dice que tal o cual persona hace bien o mal la "pega"? ¿En qué instante, a su vez, devaluamos la educación en capacitación y nos tragamos la falacia de que nos educamos solo para conseguir buenos puestos de trabajo, y en qué momento, asimismo, nos convencieron de que si trabajamos es solo para ser más ricos y para hacer más próspero al país en que vivimos?

Pero retomando el sentido de la pregunta, me gustaría decir que el malestar que se aprecia en las sociedades de nuestro tiempo no obedece en todas partes a unas mismas causas. Sí, el malestar es global, pero las causas no tienen por qué serlo, aunque querría destacar que el malestar se aprecia incluso en sociedades desarrolladas o que han alcanzado, como es el caso de Chile, buenos niveles de desarrollo. Me refiero a que no pocos creen tener derecho a la felicidad y no solo a la búsqueda de ella, un disparate que ha sido alentado por políticos que prometen trabajar, no por el desarrollo de sus pueblos y el bienestar de las personas, sino por la felicidad de estas, y por sociólogos que con no poca liviandad construyen indicadores de felicidad y hasta canastas básicas de esta, rankeando luego a los diferentes países según el grado de felicidad de quienes viven en ellos. No, no hay ningún derecho a la felicidad, y proclamar un derecho semejante por algún político o gobernante, por ejemplo, podría tener el efecto de que personas que no son felices pinten pancartas y vayan a instalarse frente a la casa de gobierno o el Congreso Nacional para que quienes trabajan en esos lugares cumplan con sus promesas y respondan a las demandas por felicidad. Solo tenemos derecho a buscar nuestra felicidad, aunque, claro, sin impedir que otros busquen la suya a su manera, y procurando no tratar nunca a otro como un medio, sino como un fin.

Otra distorsión, a mi juicio, está en el reemplazo de la realidad por las percepciones y de estas incluso por los simples estados de ánimo. ¿Quién nos convenció ahora de que lo que importa no es la realidad sino cómo la percibimos? ¿Quién nos convenció de que el grado de inseguridad real que hay en las calles, por ejemplo, es menos relevante que la percepción de inseguridad que tienen los individuos? ¿Y quiénes, sino los que se ganan la vida con ello, hacen pasar como percepciones de las personas lo que no pasa de ser un simple y fugaz estado de ánimo de quien contesta al otro lado del teléfono y emite una opinión sobre si está o de acuerdo con el Gobierno? También es del caso decir que de las encuestas hemos pasado a los simples sondeos de opinión, lo cual significa que también en esto nos hemos empobrecido.

S.M.: ¿Qué estrategias pueden pensarse para recoger, sistematizar y reflexionar sobre los modos de resolver los intereses ciudadanos tensionados y dispersos?

A.S.: La mejor estrategia, desde le punto de vista del gobierno de la sociedad, no puede ser sino la democracia y el compromiso que esta asume con los derechos 
fundamentales de las personas. Pero hay que tener en cuenta, para no decepcionarse y menos exasperarse, que la democracia es rápida en la demanda y lenta en la respuesta, a diferencia de las dictaduras que son lentas en la demanda y muy rápidas en la respuesta, a veces tanto como puede serlo un disparo lanzado a la cabeza de opositores o disidentes.

Yo no consigo entender que tantas personas, sobre todo jóvenes, bostecen ante la democracia y hasta la desprecien, en circunstancias de que se trata de la más osada de las formas de gobierno, puesto que ante la pregunta acerca de quién debe gobernar admite no tener una respuesta a priori y que puede hacerlo cualquiera que obtenga para sí la mayoría. Además, la democracia es la forma de Gobierno que mejor examen rinde en cuanto a declaración y garantía de los derechos fundamentales, de manera que quien de valor a estos - ¿y quién podría no dárselos? - tiene una muy buena razón para preferir la democracia y para no sentir horror ante la política, porque es preciso tener presente que hay algo peor que la mala política; a saber, la falta de política. Cuando la política sale de escena sabemos bien qué ocurre: entra un general vestido con uniforme regular o verde oliva -para el caso da lo mismo- que pone su pistola sobre la mesa y declara terminada toda discusión.

Y ahora dos prevenciones: la democracia es una forma de Gobierno de la sociedad, no de las instituciones, de manera que hay que tener cuidado cuando se pide democracia para el gobierno de una Universidad, de una empresa, o de cualquier otro tipo de entidades. Si con "democracia" queremos aludir a participación, bien puede y debe haber democracia en una Universidad. Pero si con democracia queremos decir principio de la mayoría como regla de oro para decidir los desacuerdos, ella nada tiene que hacer en una Universidad. También un padre puede y debe ser democrático, en el sentido de escuchar a sus hijos y hacerlos participar en los análisis que conducen a decisiones que conciernen a su familia, pero ningún padre, caso de existir y mantenerse un desacuerdo -por ejemplo, a la hora de decidir el lugar de las vacaciones-, someterá a votación el punto y legitimará sin más el punto de vista que concite la mayoría.

Y la otra prevención consiste en que si bien tenemos que mejorar la democracia representativa, haciéndola cada vez más representativa y participativa, no es del caso creer que podamos reemplazarla por una suerte de permanente democracia directa de la asamblea o derechamente de la calle o de las multitudes, donde las votaciones se produzcan a mano alzada y sin mayor diálogo, reflexión ni conciliación de intereses.

S.M.: ¿Cree posible que se produzcan alternativas filosóficas y politicas para releer el sistema globalizado en lo económico y que produce desigualdades -que se expresan en malestares micro y macrosociales-superando la estigmatización de los metarelatos?

A.S.: Siempre hay posibilidad de nuevas y mejores ideas, puesto que solo un pensador permanentemente equivocado como Fukuyama pudo creer que hemos llegado al fin de la historia. Al fin de la historia entiéndaselo, no como sucesión de los humanos acontecimientos y tampoco como disciplina que algunos cultivan y enseñan (¿cuándo los licenciados en historia empezaron a presentarse a sí mismos como historiadores?), sino fin de la historia como hallazgo de la fórmula definitiva y feliz para la organización 
de la vida en común: democracia más economía de mercado. Aunque para hacer justicia a Fukuyama, habría que decir que se trata de un pensador que junto con equivocarse corrige rápidamente sus errores, lo cual le permite publicar sucesivos libros en los que se equivoca y en los que más tarde corrige los errores de sus libros anteriores. Buen negocio para sus editores, desde luego, aunque algo desconcertante para quienes lo leen y siguen su pensamiento con interés.

Sin embargo, hacia el final de su libro más conocido (El fin de la historia y el último hombre), Fukuyama utiliza una bella y sugerente imagen que vale la pena rescatar: la de unos hombres y mujeres que, habiendo llegado en sus carretas, unas en pos de otras, a la tierra prometida de la democracia y la economía libre, se sientan por la noche a cavilar junto a la hoguera y a urdir sueños acerca de un posible mundo mejor que les haga ponerse nuevamente de pie y reanudar el viaje que creían terminado.

Hay que mantener la conversación junto a la hoguera, y me parece, siguiendo en esto a Richard Rorty, que el papel de la filosofía hoy puede consistir en conservar y prolongar esa conversación, sin ánimo de dirigirla y sin interés incluso por ocupar en ella una posición relevante. La filosofía -por decirlo de una manera metafórica- se ocuparía de llevar cada tanto tiempo leños a la hoguera, los leños que se necesitan para mantenerla encendida y para mantener igualmente viva la conversación que tiene lugar en torno a ella, evitando de ese modo que el sueño o el frío se sobrepongan al deseo de dialogar de los interlocutores.

Un mundo mejor (o peor) siempre es posible, y la globalización que hemos tenido hasta ahora -hoy en marcha algo desbocada y limitada casi exclusivamente a las finanzas, los negocios, las comunicaciones y la industria del entretenimiento- precisa de un cierto gobierno -tal como ha puesto de relieve Ernesto Ottone en su último libro-, de unas ciertas reglas conductoras que impidan que ella nos conduzca a cualquier parte, la peor de las cuales sería tanto el imperio o hegemonía de una cultura sobre las restantes o el atrincheramiento defensivo y excluyente de cada cultura en las así llamadas "identidades". El mejor destino de la globalización no puede ser otro que el cruce y mestizaje de todas las culturas, o sea, el fin de las purezas. 